\title{
GROUP KOHESIVITAS DAN GAYA KEPEMIMPINAN PEMODERASI HUBUNGAN PARTISIPASI ANGGARAN DAN SENJANGAN ANGGARAN
}

\author{
Isma Coryanata ${ }^{1)}$ \\ Fakultas Ekonomi dan Bisnis, Universitas Bengkulu \\ ismacoryanata@yahoo.com
}

\begin{abstract}
This study examined influence of group cohesiveness and the role of leadership style on the relationship between budgetary participation and budgetary slack. The samples in this study using purposive sampling. The subjects of this study are middle and lower manager in local govermment institutions including section /departement/subsection head, under the municipality and regencies in the city government of Bengkulu were amounted to 63 respondents. Hypothesis are tasted empirically used regression. The result of study indicated that, first, budgetary participation influences to budgetary slack. Second, group cohesiveness as moderating variable in the relation of budgetary participation with budgetary slack. Third, the role of leadership syle as moderating variable in the relation of budgetary participation with budgetary slack. Therefore this study sported anothetr studies before.
\end{abstract}

Keywords: budgetary participation, budgetary slack, group cohesiveness, the role of leadership style

\section{PENDAHULUAN}

Pertanggung jawaban pemerintah daerah terdiri dari pertanggungjawaban vertikal kepada pemerintah pusat dan pertanggungjawaban horizontal kepada masyarakat terhadap fungsi penyusunan anggaran. Anggaran dalam pemerintahan digunakan sebagai dokumen atau kontrak untuk kesepakatan dan komitmen yang telah dibuat oleh pemerintah atas penggunaan dana publik untuk kepentingan tertentu. Anggaran sektor publik merupakan pelaksanaan program dan pengelolaan dana publik yang didanai oleh kas Negara. Brownell (1983) dalam Sumarno (2005) anggaran melibatkan kinerja serta hubungan diantara manusia, sehingga terdapat perilaku manusia yang mempengaruhi anggaran tersebut. Teori keagenan menyatakan dalam organisasi terdapat suatu huhungan dalam pekerjaan yang melibatkan seorang atasan dengan bawahannya. Dalam pemerintahan sektor publik, principal yaitu atasan/Kepala SKPD, dan agent yaitu bawahan/pegawai SKPD. Hubungan antara atasan dan bawahan dapat mengarah pada kondisi dimana masing-masing memiliki kepentingan yang berbeda terhadap organisasi. Perbedaan tersebut menyebabkan terciptanya suatu senjangan.

Senjangan pada anggaran didefinisikan sebagai selisih antara sumber daya sesungguhnya untuk menyelesaikan pekerjaan dengan efektif, dengan sejumlah sumber daya yang ditambahkan untuk menyelesaikan pekerjaan tersebut (Arfan, 2010). Seseorang melakukan senjangan pada anggaran dengan memperkirakan pendapatan lebih rendah dan biaya lebih tinggi atau dapat juga dilakukan dengan menaikkan biaya maupun merendahkan pendapatan dari yang semestinya agar dapat mencapai target anggaran dengan mudah. Banyak penelitian yang dilakukan untuk menganalisa faktor-faktor yang dapat menimbulkan senjangan anggaran. Salah satu faktor yang banyak diteliti dan dianggap memiliki pengaruh positif senjangan pada anggaran adalah partisipasi anggaran diantaranya penelitian Young (1985), Nouri and Parker (1995), Falikhatun (2007), Zhang dan Zhou (2010), Widyaningsih (2011), serta Aprila dan Handayani (2012). Akan tetapi banyak penelitian lainnya yang mendapatkan hasil bahwa partisipasi anggaran mempunyai pengaruh negatif terhadap terjadinya senjangan diantaranya penelitian Merchant (1985), Dunk (1993), Kren and Maiga 
(2007). Perbedaan hasil penelitian yang ada dapat diselesaikan melalui pendekatan kontingensi. Pendekatan ini dapat menambah variabel lain sebagai variabel moderating. Dalam penelitian ini, digunakan variabel group kohesivitas dan gaya kepemimpinan untuk menguji hubungan antara partisipasi anggaran dengan senjangan anggaran.

Group kohesivitas merupakan tingkat yang mendeskripsikan sebuah kelompok dengan anggota yang memiliki keterikatan antar anggota yang lain dan berkeinginan untuk tetap menjadi bagian dari kelompok. Tingkat kohesivitas bisa mempunyai akibat positif atau negatif tergantung seberapa baik tujuan kelompok sesuai dengan tujuan organisasi formal. Bila kohesivitas tinggi dan kelompok menerima serta sepakat dengan tujuan formal organisasi, maka perilaku kelompok akan positif ditinjau dari sisi organisasi formal. Hal ini tentunya akan dapat mengurangi terjadinya senjangan anggaran dalam suatu perusahaan

Gaya kepemimpinan yaitu cara seseorang untuk memberikan arahan pada orang lain sehingga orang tersebut dengan ikhlas menuruti kehendaknya agar tercapainya tujuan organisasi Luthans. Apabila pemimpin berorientasi pada hubungan yaitu pemimpin mempunyai hubungan baik dengan bawahannya, maka bawahan akan merasa bebas dan tidak akan takut jika mereka membuat suatu senjangan. Pernyataan tersebut sejalan dengan hasil penelitian Ikhsan (2007) yang menyatakan bahwa gaya kepemimpinan memperkuat hubungan partisipasi anggaran terhadap senjangan anggaran. Berbeda dengan hasil yang didapatkan Ramadhina (2007), Himawan dan Ika (2010), Widyaningsih (2011), dan Rosalina (2012) yang menyatakan gaya kepemimpinan yang berorientasi pada tugas dapat memperlemah hubungan antara partisipasi anggaran terhadap senjangan anggaran.

Rumusan masalah dalam penelitian ini adalah (1) apakah partisipasi anggaran berpengaruh positif terhadap senjangan anggaran, (2) apakah grup kohesivitas akan memperlemah hubungan antara partisipasi anggaran dengan senjangan anggaran, (3) apakah gaya kepemimpinan memperlemah hubungan antara partisipasi anggaran dengan senjangan anggaran.

Hasil penelitian ini diharapkan dapat memberikan sumbangan pemikiran bagi pemerintah Kota Bengkulu dalam rangka penerapan anggaran berbasis kinerja serta dapat menjadi masukan dan referensi bagi peneliti lain yang berminat dan tertarik memperdalam penelitian akuntansi, khususnya konsentrasi akuntansi sektor publik.

\section{KERANGKA TEORITIS DAN HIPOTESIS}

Agency theory merupakan konsep yang menjelaskan hubungan kontraktual antara principal dan agent (Jensen dan Meckling, 1976). Riyanto (2003) mengatakan perlunya penelitian mengenai pendekatan kontijensi dalam menguji konsektual yang mempengaruhi hubungan antara sistem pengendalian dengan kinerja salah satunya anggaran.

\section{Partisipasi Anggaran, Senjangan Anggaran, Group Kohesivitas, dan Gaya Kepemimpinan}

Falikhatun (2007) menyatakan bahwa partisipasi penganggaran berpengaruh positif terhadap senjangan anggaran. Young dalam Falikhatun (2007) menyatakan partisipasi anggaran menyebabkan senjangan anggaran. Adanya partisipasi anggaran maka akan menyebabkan melonggarkan anggaran yang disusun agar mudah dicapai dengan menurunkan pendapatan dan menaikkan biaya pada proses penyusunan anggaran. Coryanata (2006: 2013) juga menemukan adanya pengaruh positif antara partisipasi anggaran dengan senjangan anggaran. Berdasarkan penjelasan di atas maka hipotesis 1 yang diajukan sebagai berikut:

$\mathrm{H}_{1}$ : Partisipasi anggaran berpengaruh positif terhadap senjangan anggaran.

Konsep kohesivitas penting untuk pemahaman sebuah kelompok dalam organisasi. Semakin para anggota kelompok saling tertarik dan makin sepakat terhadap sasaran 
kelompok, maka akan semakin lekat atau semakin kohesif kelompok tersebut. Tingkat kohesivitas bisa mempunyai akibat positif atau negatif tergantung seberapa baik tujuan kelompok sesuai dengan tujuan organisasi formal. Bila kohesivitas tinggi dan kelompok menerima serta sepakat dengan tujuan formal organisasi, maka perilaku kelompok akan positif ditinjau dari sisi organisasi formal. Tetapi bila kelompok sangat kohesif tetapi tujuannya tidak sejalan dengan organisasi formal, maka perilaku kelompok akan negatif ditinjau dari sisi organisasi formal (Robbins, 1996). Dalam kaitannya dengan proses partisipasi penyusunan anggaran, apabila tujuan kelompok dengan kohesivitas yang tinggi sesuai dengan tujuan manajemen organisasi, maka perilaku kelompok terhadap organisasi akan positif dan cenderung untuk tidak menciptakan senjangan anggaran. Berdasarkan penjelasan di atas maka hipotesis 2 yang dikembangkan sebagai berikut:

$\mathrm{H}_{2}$ : Group kohesivitas memperlemah hubungan antara partisipasi anggaran dengan senjangan anggaran.

Dalam mengklasifikasikan gaya kepemimpinan, Fiedlers telah mengembangkan suatu indeks yang disebut skala the Least-Preferred Coworker (LPC). Skor LPC tinggi menunjukkan bahwa pemimpin memiliki orientasi hubungan antar manusia, sedangkan skor LPC rendah menunjukkan orientasi tugas. Apabila pemimpin berorientasi pada hubungan yaitu pemimpin mempunyai hubungan baik dengan bawahannya, maka bawahan akan merasa bebas dan tidak akan takut jika mereka membuat suatu senjangan. Pernyataan tersebut sejalan dengan hasil penelitian Ikhsan (2007) dan Yunas (2010) yang menyatakan bahwa gaya kepemimpinan memperkuat hubungan partisipasi anggaran terhadap senjangan anggaran. Berbeda dengan hasil yang didapatkan Ramadhina (2007), Himawan dan Ika (2010), Widyaningsih (2011), dan Rosalina (2012) yang menyatakan gaya kepemimpinan yang berorientasi pada tugas dapat memperlemah hubungan antara partisipasi anggaran terhadap senjangan anggaran. Sedangkan Dismayanti (2009) dan Merril (2010) menyatakan partisipasi anggaran dengan senjangan anggaran tidak dimoderasi oleh gaya kepemimpinan. Berdasarkan penjelasan di atas maka hipotesis yang dikembangkan sebagai berikut:

$\mathrm{H}_{3}$ : Gaya kepemimpinan memperlemah hubungan antara partisipasi anggaran terhadap senjangan anggaran.

Dari uraian di atas maka dapat dibuatkan kerangka penelitian seperti pada berikut :

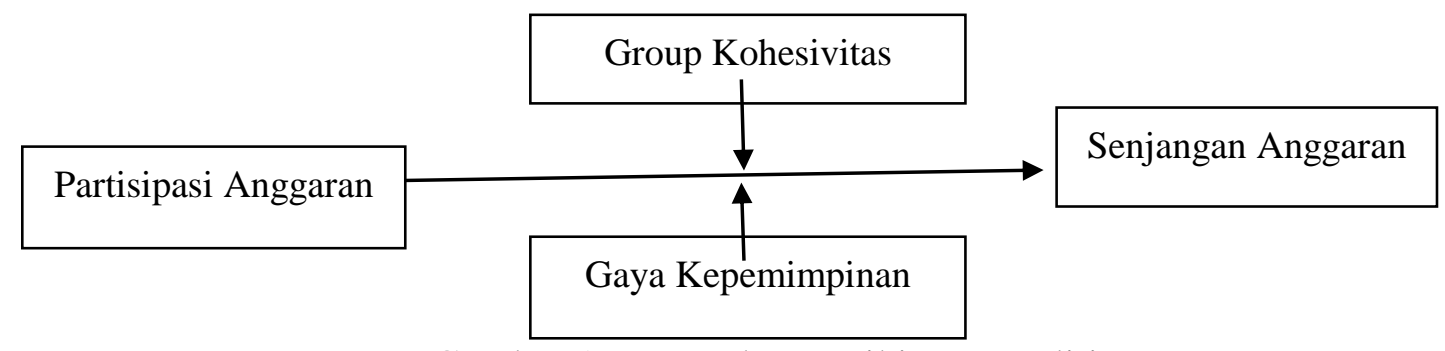

Gambar 1. Kerangka Pemikiran Penelitian

\section{METODE PENELITIAN}

\section{Data Penelitian}

Obyek penelitian ini adalah pemerintahan Kota Bengkulu. Data penelitian diperoleh dari data primer melalui metode survei. Responden penelitian ini merupakan manajer tingkat menengah dan tingkat bawah dari pemerintah daerah yaitu pejabat setingkat kepala, kepala bagian/bidang/sub dinas dan kepala sub bagian/sub bidang/seksi dari badan, dinas, dan kantor 
yang terlibat dalam penyusunan anggaran di pemerintahan Kota Bengkulu. Pengambilan sampel dilakukan dengan cara random sampling sebanyak 63 responden dari 82 kuesioner yang disebar.

\section{Pengumpulan Data}

Pengumpulan data primer melalui metode survei dengan melakukan penyebaran kuesioner pada pejabat setingkat kepala, kepala bagian/bidang/subdinas dan kepala su;bbagian/subbidang/seksi dari badan, dinas, dan kantor di pemerintahan Kota Bengkulu dengan distribusinya pada tabel berikut ini.

Tabel 1. Jumlah Sampel dan Tingkat Pengembalian Kuesioner

\begin{tabular}{l|c}
\hline \multicolumn{1}{c|}{ Keterangan } & Jumlah \\
\hline Total penyebaran kuesioner & 82 \\
\hline Jumlah kuesioner yang tidak dikembalikan & 17 \\
\hline Jumlah kuesioner yang dikembalikan & 65 \\
\hline Jumlah kuesioner yang tidak diisi lengkap & 3 \\
\hline Total pengembalian kuesioner yang dioleh & 63 \\
\hline Response Rate (Tingkat Pengembalian) & $79 \%$ \\
\hline
\end{tabular}

Sumber: Data Primer, diolah, 2016

\section{HASIL DAN PEMBAHASAN}

Kuesioner yang disebarkan pada 82 responden dari 41 instansi di Pemerintahan Kota Bengkulu. Kuesioner yang dikembalikan sejumlah 65 eksemplar (response rate $=79 \%$ ). Kuesioner yang terisi dengan baik dan lengkap sehingga data yang digunakan untuk analisis data sebanyak 63 kuesioner.

\section{Uji Validitas dan Reliabilitas}

Uji validitas dilakukan dengan melihat nilai pearson corelation. Berdasarkan analisis diperoleh nilai pearson corelation partisipasi anggaran yaitu sekitar 0,470-0,853>0,30. Nilai pearson corelation group kohesivitas yaitu sekitar 0,693-0,852>0,30 Nilai pearson corelation gaya kepemimpinan sebesara $0.637-0,758>0,30$. Nilai pearson correlation senjangan anggaran berkisar antara 0,530-0,753 > 0,30. Dengan demikian, seluruh pernyataan kuesioner penelitian ini valid. Uji reliabilitas dilakukan dengan melihat nilai cronbach's alpha. Berdasarkan analisis diperoleh nilai cronbach's alpha partisipasi anggaran, group kohevisitas, gaya kepemimpinan dan senjangan anggaran sebesar 0,$754 ; 0,843 ; 0,686$; serta 0,694, sehingga seluruh cronbach's alpha untuk masing-masing variabel > 0,60. Dengan demikian, keseluruhan dari pernyataan kuesioner penelitian reliabel.

\section{Pengujian Asumsi Klasik}

\section{Pengujian Multikolinearitas}

Multikolinearitas adalah suatu keadaan yang menggambarkan adanya hubungan linear yang sempurna atau pasti diantara beberapa atau semua variable independen dari model yang diteliti (Damodar, 1995). Multikolinearitas akan mengakibatkan koefisien regresi tidak pasti atau mengakibatkan kesalahan standarnya menjadi tidak terhingga sehingga menimbulkan bias spesifikasi.

Hair dkk (1995) menawarkan cara untuk mengetahui ada tidaknya multikolinearitas ini, yaitu dengan melihat besarnya nilai tolerance value (VIF). Apabila 
nilai VIF $<10$ dan nilai tolerance mendekati angka satu, ini menunjukkan tidak terjadi multikolinearitas. Ringkasan hasil pengujian ini dapat dilihat pada tabel 4 di bawah ini.

Tabel 4

Hasil Pengujian Multikolinearitas

\begin{tabular}{l|c|c|c}
\hline \multirow{2}{*}{ Variabel } & \multicolumn{2}{|c|}{ Collinearity Statistics } & \multirow{2}{*}{ Ket } \\
\cline { 2 - 3 } & Tolerance & VIF & \\
\hline Partisipasi Anggaran & 0,195 & 3,383 & Bebas \\
Group Kohevisitas & 0,176 & 6,852 & Bebas \\
Gaya Kepemimpinan & 0,271 & 4,685 & Bebas \\
\hline
\end{tabular}

Dari hasil tabel 4 dapat dikatakan bahwa model regresi tersebut telah memenuhi asumsi multikolinearitas.

\section{Pengujian Kenormalan Data}

Pengujian normalitas data dilakukan dengan menggunakan Kolmogorof-Smirnof pada alpha sebesar 5\%. Jika nilai signifikansi dari pengujian Kolmogorof-Smirnof lebih besar dari 0.05 berarti data normal. Ringkasan hasil pengujian dapat dilihat pada tabel 5 di bawah ini.

Tabel 5

Hasil Pengujian Kenormalan Data

\begin{tabular}{c|c|c|c}
\hline Variabel & N & Signifikansi & Keterangan \\
\hline Partisipasi Anggaran (PA) & 63 & 0,268 & Normal \\
Senjangan Anggaran (SA) & 63 & 0,395 & Normal \\
Group Kohevisitas (GKo) & 63 & 0,184 & Normal \\
Gaya Kepemimpinan (GKp) & 63 & 0,239 & Normal \\
\hline
\end{tabular}

Dari hasil di atas secara umum $p$-value nya lebih besar dari 0,05 dan ini menunjukkan data yang digunakan adalah normal.

\section{Pengujian Regresi Berganda}

Tabel 6 Hasil Analisis Regresi Linear Berganda

\begin{tabular}{|c|c|c|c|c|c|c|}
\hline & \multirow{2}{*}{ Model } & \multicolumn{2}{|c|}{ Unstandardized Coefficients } & \multirow{2}{*}{$\begin{array}{c}\text { Standardized } \\
\text { Coefficients }\end{array}$} & \multirow{2}{*}{$\mathrm{t}$} & \multirow{2}{*}{ Sig. } \\
\hline & & $\mathrm{B}$ & Std. Error & & & \\
\hline \multirow[t]{6}{*}{1} & (Constant) & 1.482 & 1.108 & & 1.048 & .437 \\
\hline & PA & .528 & .473 & .452 & .642 & .019 \\
\hline & GKo & .432 & .374 & .327 & .868 & .021 \\
\hline & GKp & .638 & .385 & .539 & .748 & .006 \\
\hline & PA*GKo & -.717 & .538 & -.636 & -.735 & .027 \\
\hline & PA*GKp & -.685 & .597 & -.472 & -.893 & .031 \\
\hline \multicolumn{2}{|c|}{$\mathrm{F}$} & \multicolumn{5}{|l|}{4.374} \\
\hline \multicolumn{2}{|c|}{ Sig F } & \multicolumn{5}{|l|}{0.000} \\
\hline \multicolumn{2}{|c|}{ R Square } & \multirow{2}{*}{\multicolumn{2}{|c|}{$\begin{array}{l}0.589 \\
0.516\end{array}$}} & & & \\
\hline & usted & & & & & \\
\hline
\end{tabular}


Square

a. Dependent Variable: $Y$

Sumber: Data primer diolah 2016

\section{Uji Nilai t Statistik}

\section{Pengujian Hipotesa Pertama}

Hipotesis pertama menyatakan bahwa "Partisipasi anggaran berpengaruh positif terhadap budgetary slack". Untuk membuktikan hipotesis pertama ini bisa dilihat dari tabel 6. Hasil pengujian $\mathrm{H}_{1}$ diperoleh nilai koefisien positif 0.528 dan nilai t sebesar 0.642 dengan sig 0.019 $<\alpha 0.05$. Dengan demikian hipotesis pertama diterima.

\section{Pengujian Hipotesa Kedua}

Hipotesis kedua menyatakan bahwa "group kohevisitas memperlemah hubungan partisipasi anggaran dan senjangan anggaran. Untuk membuktikan hipotesis kedua ini bisa dilihat dari tabel 6. Hasil pengujian $\mathrm{H}_{2}$ diperoleh nilai koefisien negatif 0.717 dan nilai $\mathrm{t}$ sebesar - 0.735 dengan sig $0.027<\alpha 0.05$. Dengan demikian hipotesis kedua diterima. Dengan adanya group kohevisitas dalam Pemerintahan Kota Bengkulu, maka akan memperkecil terjadinya senjangan anggaran walaupun anggaran yang disusun berdasarkan partispasi anggaran.

\section{Pengujian Hipotesa Ketiga}

Hipotesis ketiga menyatakan bahwa "gaya kepemimpinan memperlemah hubungan antara partisipasi anggaran dengan senjangan anggaran. Untuk membuktikan hipotesis ketiga ini bisa dilihat dari tabel 6. Hasil pengujian $\mathrm{H}_{3}$ diperoleh nilai koefisien negatif 0.685 dan nilai $t$ sebesar -0.893 dengan sig $0.031<\alpha 0.05$. Dengan demikian hipotesis ketiga diterima. Dengan adanya gaya kepemimpjnan dalam Pemerintahan Kota Bengkulu, maka akan memperkecil terjadinya senjangan anggaran walaupun anggaran yang disusun berdasarkan partispasi anggaran.

\section{Uji Nilai F Statistik}

Dari tabel 6 di atas dapat dilihat bahwa nilai F sebesar 4.374 dan sig F $0.000<\alpha 0.05$ artinya model yang digunakan adalah layak/fit terhadap group kohevisitas dan gaya kepemimpinan memperlemah hubungan antara partisipasi anggatan dengan senjangan anggaran.

\section{Uji Determinasi}

Dari tabel 6 di atas dapat dilihat bahwa besarnya adjusted $\mathrm{R}^{2}$ adalah sebesar 0.516 yang artinya bahwa $51,6 \%$ variabel senjangan anggaran dapat dijelaskan oleh variabel partisipasi anggaran, group kohevisitas, dan gaya kepemimpinan dan sisanya $48.4 \%$ dipengaruhi oleh variabel lain yang tidak diteliti.

\section{PENUTUP}

Kesimpulan dari penelitan ini sebagai berikut: (1) dengan adanya partisipasi anggaran ternyata membuat peluang bawahan untuk melakukan budgetary slack semakin besar, (2) dengan adanya group kohevisitas akan memperlemah hubungan partispasi anggaran dengan senjangan anggaran, (3) dengan adanya gaya kepemimpinan akan memperlemah hubungan partisipasi anggaran dengan senjangan anggaran. 


\section{SARAN}

Peneliti menyadari bahwa dalam penelitian ini masih jauh dari sempurna, oleh karena itu ada beberapa saran yang perlu dikemukakan untuk memperbaiki penelitian berikutnya, diantaranya: (1) penelitian berikutnya sebaiknya dalam memperoleh data dilakukan dengan wawancara langsung sehingga data yang diperoleh akan lebih lengkap dan sesuai dengan harapan, (2) menggunakan sampel yang lebih besar dengan cakupan wilayah yang lebih luas, sehingga hasil kesimpulan penelitian dapat digeneralisasi, (3) penelitian berikutnya dapat menggunakn variable lain untuk melihat pengaruh partisipasi penyusunan anggaran terhadap budgetary slack seperti keadilan prosedural.

\section{DAFTAR PUSTAKA}

Aprila, Nila dan Hidayani, Selvi. 2012. The Effect Of Budgetary Participation, Asymmetry Information, Budget Emphasis, And Comitment Organization To Budgetary Slack At SKPD Governmental Of Bengkulu City. MIICEMA Prociding. Malaysia.

Arfan, Ikhsan. 2011. Akuntansi Keperilakuan. Edisi 2. Jakarta: Salemba Empat.

Brownell, Peter. 1982. The Role of Accounting Data in Performance Evaluation, Budgetary Participate and Organizational Effectiveness. Journal of Accounting Research.

Brownell, Peter. 1983. Leadership Style, Budgetary Participation and Managerial Behavior, Accounting, Organizations and Society. Vol.8. No.4. pp. $307-321$.

Coryanata, Isma, 2006. Desentralisasi dan Komitmen Organisasi sebagai Pemoderasi Hubungan antara Partisipasi Penyusunan Anggaran dan Kinerja Manajerial pada Perguruan Tinggi Swasta di Indonesia. Jurnal Akuntansi dan Investasi FE UMY Yogyakarta, Vol. 1 Januari. Hal 73-88

2013. Komitmen Organisasi, Desentralisasi dan Budaya Organisasi terhadap Hubungan Partisipasi Anggaran dengan Senjangan Anggaran. Jurnal Management Insight. Volume 8, Nomor 1.

Dunk, A. S. 1993. The Effect of Budget Emphasis and Information Asymetry on Relation Between Budgetary Participation and Slack. The Accounting Review.

Falikhatun. 2007. Interaksi Informasi Asimetri, Budaya Organisasi dan Group Cohesiveness dalam Hubungan antara Partisipasi Anggaran dan Budgetary Slack (Studi Kasus pada Rumah Sakit Umum Daerah Se-Jawa Tengah). SNA X: Makasar.

Himawan, Albertus Kukuh dan Ika, Ardianu S. 2010. Pengaruh Komitmen Organisasi, Gaya Kepemimpinan, Dan Job Relevant Information (JRI) Terhaap Hubungan Antara Partisipasi Anggaran Dan Kinerja Manajerial. Jurnal Ekonomi dan Bisnis, Vol.5 No. 9

Ikhsan, Arfan dan Ana. 2007. Pengaruh Partispasi Angggaran Terhadap Senjangan Angggaran Dengan Menggunakan 5 Variabel Pemoderasi. Symposium Nasional Akuntansi X Makasar.

Jensen dan Meckling. 1976. Theory of Firm Managerial Behavior, Agency Cost and Ownership Structure. Journal of Financial Economic. 
Kren, Leslie and Maiga, Adam S. 2007. The Intervening Effect Of Information Asymetry On Budget Prticipation And Segment Slack. Management Accounting, Volume 16.h:141157.

Latuheru, Belianus Patria. 2006. Pengaruh Partisipasi Anggaran Terhadap Senjangan Anggaran dengan Komitmen Organisasi sebagai Variabel Moderating (Studi Empiris pada Kawasan Industri Maluku). Jurnal Akuntansi dan Sistem Teknologi Informasi Vol. 5, No. 1, April 2006: 24-38.

Merchant, KA. 1985. Budgeting and Propensity to Create Slack. Accounting Organization and Society.

Nouri, Hossein and Parker, Robert J. 1996. The Effect of Organizational Commitment on The Ralation Between Budgetary Participation and Budgetary Slack. Behavioral Research in Accounting. Vol. 8. Printed in USA. pp. $76-90$.

Sumarnoo, J. 2005. Pengaruh Kmitmen \& Gaya Kpemimpinan Terhadap Hub. Antara Partispasi Angggaran Dan Kinerja Mnajerial (Study Empiris di Kantor Cabang Perbankkan Indonesiaa di Jakarta). SNA VIII Solo, 15-16 September 2005

Riyanto, B. 2003. Model Kontijensi Sistem Pengendalian: Integrasi dan Ekstensi untuk Future Reseach. KOMPAK: Jurnal Akuntansi, Manajemen, dan Sistem Informasi FE UTY Yogyakarta. No: 9. April. 330-342.

Robbins, Stephen P. 1996. Perilaku Organisasi. Terjemahan. Jakarta: PT Prenhallindo.

Ramadhina, Westhi. 2007. Pengaruh Partisipasi Anggaran Terhaap Senjangan Anggaran Dengan Gaya Kepemimpinan Dan Budaya Organisasi Sebagai Variabel Pemoderasi (Studi Empiris pada Satuan Kerja Perangkat Daerah Kota Payakumbuh). Skripsi Sarjana Jurusan Akuntansi Pada Fakultas Ekonomi Universitas Negeri Padang.

Rosalina. 2012. Pengaruh Partisipasi Anggaran Terhadap Senjangan Anggaran (Budgetary Slack) Dengan Informasi Asimetri, Gaya Kepemimpinan, Dan Komitmen Organisasi Sebagai Variabel Moderating (Studi Empiris pada Pemerintah Kota Dumai). Skripsi Sarjana Jurusan Akuntansi Fakultas Ekonomi Universitas Riau.

Widyaningsih, Aristanti. 2011. Moderasi Gaya Kepemimpinan atas Pengaruh Partisipasi Anggaran terhadap Budgetary Slack. Fokus Ekonomi Vol.6 No.1.h:1-18

Young, S. M. 1985. Participatif Budgeting: The Efects of Riks Aversion and Asimmetris Information of Budgetary Slak. Journal of Acounting Reserch 23:829-842.

Zhang, Shuangcai. Zhou, Wenjun. 2010. Research on Present Situation of Budgetary Slack in Chinese Enterprise. School of Management, Hebei University, P.R.China. 